\title{
REALIZED VOLATILITY: A REVIEW
}

\author{
Michael McAleer ${ }^{1}$ and Marcelo C. Medeiros ${ }^{2}$ \\ ${ }^{1}$ School of Economics and Commerce, University of Western Australia \\ ${ }^{2}$ Department of Economics, Pontifical Catholic University of Rio de Janeiro, \\ Rio de Janeiro, Brasil
}

\begin{abstract}
This article reviews the exciting and rapidly expanding literature on realized volatility. After presenting a general univariate framework for estimating realized volatilities, a simple discrete time model is presented in order to motivate the main results. A continuous time specification provides the theoretical foundation for the main results in this literature. Cases with and without microstructure noise are considered, and it is shown how microstructure noise can cause severe problems in terms of consistent estimation of the daily realized volatility. Independent and dependent noise processes are examined. The most important methods for providing consistent estimators are presented, and a critical exposition of different techniques is given. The finite sample properties are discussed in comparison with their asymptotic properties. A multivariate model is presented to discuss estimation of the realized covariances. Various issues relating to modelling and forecasting realized volatilities are considered. The main empirical findings using univariate and multivariate methods are summarized.
\end{abstract}

Keywords Continuous time processes; Finance; Financial econometrics; Forecasting; High frequency data; Quadratic variation; Realized volatility; Risk; Trading rules.

JEL Classification C13; C14; C22; C53.

\section{INTRODUCTION}

Given the rapid growth in financial markets and the continual development of new and more complex financial instruments, there is an ever-growing need for theoretical and empirical knowledge of the volatility in financial time series. It is widely known that the daily returns of financial assets, especially of stocks, are difficult, if not impossible, to predict, although the volatility of the returns seems to be relatively easier to forecast. Therefore, it is hardly surprising that financial econometrics,

Address correspondence to Marcelo C. Medeiros, Department of Economics, Pontifical Catholic University of Rio de Janeiro, Rio de Janeiro, Brasil; E-mail: mcm@econ.puc-rio.br 
in particular the modeling of financial volatility, has played such a central role in modern pricing and risk management theories.

There is, however, an inherent problem in using models where the volatility measure plays a central role. The conditional variance is latent, and hence is not directly observable. It can be estimated, among other approaches, by the (Generalized) Autoregressive Conditional Heteroskedasticity, or (G)ARCH, family of models proposed by Engle (1982) and Bollerslev (1986), stochastic volatility (SV) models (see, for example, Taylor, 1986), or exponentially weighted moving averages (EWMA), as advocated by the Riskmetrics methodology (Morgan, 1996) (see McAleer, 2005 for a recent exposition of a wide range of univariate and multivariate, conditional and stochastic, models of volatility, and Asai et al. (2006) for a review of the growing literature on multivariate stochastic volatility models). However, as observed by Bollerslev (1987), Malmsten and Teräsvirta (2004), and Carnero et al. (2004), among others, most of the latent volatility models fail to describe satisfactorily several stylized facts that are observed in financial time series.

An empirical fact that standard latent volatility models fail to describe in an adequate manner is the low, but slowly decreasing, autocorrelations in the squared returns that are associated with high excess kurtosis of returns. Correctly describing the dynamics of the returns is important in order to obtain accurate forecasts of the future volatility which, in turn, is important in risk analysis and management. In this sense, the assumption of Gaussian standardized returns has been refuted in many studies, and heavy-tailed distributions have instead been used.

The search for an adequate framework for the estimation and prediction of the conditional variance of financial assets returns has led to the analysis of high frequency intraday data. Merton (1980) noted that the variance over a fixed interval can be estimated arbitrarily, although accurately, as the sum of squared realizations, provided the data are available at a sufficiently high sampling frequency. More recently, Andersen and Bollerslev (1998) showed that ex post daily foreign exchange volatility is best measured by aggregating 288 squared fiveminute returns. The five-minute frequency is a trade-off between accuracy, which is theoretically optimized using the highest possible frequency, and microstructure noise that can arise through the bid-ask bounce, asynchronous trading, infrequent trading, and price discreteness, among other factors (see Madhavan, 2000; Biais et al., 2005 for very useful surveys on this issue).

Ignoring the remaining measurement error, which can be problematic, the ex post volatility essentially becomes "observable." Andersen and Bollerslev (1998), Hansen and Lunde (2005a), and Patton (2005) used this new volatility measure to evaluate the out-of-sample forecasting 
performance of GARCH models. ${ }^{1}$ As volatility becomes "observable," it can be modeled directly, rather than being treated as a latent variable. Based on the theoretical results of Barndorff-Nielsen and Shephard (2002), Andersen et al. (2003), and Meddahi (2002), several recent studies have documented the properties of realized volatilities constructed from high frequency data. However, as will be discussed later, microstructure effects introduce a severe bias on the daily volatility estimation. Aït-Sahalia et al. (2005), Bandi and Russell (2005a, 2006b), Zhang et al. (2005), and Hansen and Lunde (2006b), among others, have discussed various solutions to the inconsistency problem.

The purpose of this article is to provide a critical review of the major theoretical and empirical developments in the exciting and rapidly expanding literature on realized volatility $(\mathrm{RV}) .^{2}$ Although several excellent review articles have been written recently, the review given in this article differs from the others in a number of respects. Some of the surveys are rather broad, and review volatility in general, such Poon and Granger (2003), Andersen et al. (2006a,b). Furthermore, most of these articles have not taken account of the microstructure noise. This review article focuses only on the RV literature and carefully addresses the crucial problem of measurement error. Bandi and Russell (2006a) have also reviewed the RV literature, with an emphasis on microstructure noise. However, Bandi and Russell (2006a) placed more emphasis on the noise component and its economic determinants. Barndorff-Nielsen and Shephard (2007) extensively reviewed the literature on nonparametric estimation of volatility. In their excellent review, the authors have focused on the theoretical foundations of the estimators that have been proposed recently. They largely (but not exclusively) focused on the frictionless case with and without the effects of jumps.

The purpose of this review article is to fill the gap in the literature for the practitioner, to discuss the issues of modeling and forecasting daily realized volatilities, and to present the strengths and limitations of the various approaches that are available in the literature. The main findings in the literature are reviewed, different modeling strategies are suggested, and model evaluation is also considered. Finally, the most important practical applications are presented. As the literature is extensive, we have decided not to include jumps in the review for purposes of being concise.

\footnotetext{
${ }^{1}$ Hansen and Lunde (2006a) showed that substituting an imperfect measure of volatility can distort (or even reverse) the empirical ranking of volatility models.

${ }^{2}$ Other empirical quantities include the bi-power variation and multipower variation that are particularly useful for detecting jumps (see Andersen et al., 2007; Barndorff-Nielsen and Shephard, 2004a, 2005a,b; Barndorff-Nielsen et al., 2006c; Bollerslev et al., 2005; Huang and Tauchen, 2005; Tauchen and Zhou, 2004), and the intraday range-based estimators (see Christensen and Podolskij, 2006a,b; van Dijk and Martens, 2007).
} 
We recommend Barndorff-Nielsen and Shephard (2004a, 2007) for the case of various models of jump processes.

The article is organized as follows. In Section 2 we present the general univariate framework for estimating realized volatilities. A simple discrete time model is presented in Section 2.1 to motivate and define the basic notation, a continuous time model which gives the theoretical foundations for the main results in this literature are presented in Section 2.2, and the effects of microstructure noise and RV estimation are discussed in detail in Section 2.3, where both independent and dependent noise processes are considered. In Section 3 the main solutions for tackling the problem of microstructure noise are presented. Section 4 presents a multivariate model, and briefly discusses the estimation of the realized covariances. The issues of modeling and forecasting realized volatilities are considered in Section 5. Finally, some concluding remarks are given in Section 6.

\section{THE GENERAL UNIVARIATE FRAMEWORK}

This section presents a simple discrete time model to motivate the RV estimator. Section 2.1 closely follows the structure of Oomen (2002). A continuous time model, which forms the basis of much of the theoretical results, is presented in Section 2.2. The discussion starts with the case without noise (that is, with no measurement errors), then proceeds to incorporate microstructure noise.

\subsection{The Early Days-A Simple Discrete Time Model}

Consider a simple discrete time model in which the daily returns of a given asset are typically characterized as

$$
r_{t}=h_{t}^{1 / 2} \eta_{t}
$$

where $\left\{\eta_{t}\right\}_{t=1}^{T}$ is a sequence of independently and normally distributed random variables with zero mean and unit variance, $\eta_{t} \sim \operatorname{NID}(0,1)$.

Suppose that, in a given trading day $t$, the logarithmic prices are observed tick-by-tick. Consider a grid $\Lambda_{t}=\left\{\tau_{0}, \ldots, \tau_{n_{t}}\right\}$ containing all observation points, and set $p_{t, i}, i=1, \ldots, n_{t}$, to be the $i$ th price observation during day $t$, where $n_{t}$ is the total number of observations at day $t$. Furthermore, suppose that

$$
r_{t, i}=h_{t, i}^{1 / 2} \eta_{t, i}
$$


where $\eta_{t, i} \sim \operatorname{NID}\left(0, n_{t}^{-1}\right), r_{t, i}=p_{t, i}-p_{t, i-1}$ is the $i$ th intraperiod return of day $t$ such that

$$
r_{t}=\sum_{i=0}^{n_{t}} r_{t, i}
$$

and

$$
h_{t}=\frac{1}{n_{t}} \sum_{i=1}^{n_{t}} h_{t, i}
$$

Define the information set $\Im_{t, i} \equiv \Im\left\{p_{a, b}\right\}_{a=-\infty, b=0}^{a=t, b=i}$ as the $\sigma$-algebra generated by all the information to the $i$ th tick in day $t$. Therefore, $\mathfrak{\Im}_{t, 0}$ is the information set available prior to the start of day $t$. It follows that $\mathrm{E}\left(r_{t}^{2} \mid \mathfrak{\Im}_{t, 0}\right)=h_{t}$ and $\mathrm{V}\left(r_{t}^{2} \mid \mathfrak{\Im}_{t, 0}\right)=2 h_{t}^{2}$.

The realized variance is defined as the sum of all available intraday high frequency squared returns given by

$$
R V_{t}^{(\text {all })}=\sum_{i=0}^{n_{t}} r_{t, i}^{2}
$$

The squared daily return can be written as

$$
r_{t}^{2}=\left(\sum_{i=0}^{n_{t}} r_{t, i}\right)^{2}=\sum_{i=0}^{n_{t}} r_{t, i}^{2}+2 \sum_{i=0}^{n_{t}-1} \sum_{j=i+1}^{n_{t}} r_{t, i} r_{t, j},
$$

such that

$$
\begin{aligned}
\mathrm{E}\left(r_{t}^{2} \mid \Im_{t, 0}\right) & =\mathrm{E}\left(\sum_{i=0}^{n_{t}} r_{t, i}^{2} \mid \Im_{t, 0}\right)+2 \mathrm{E}\left(\sum_{i=0}^{n_{t}-1} \sum_{j=i+1}^{n_{t}} r_{t, i} r_{t, j} \mid \Im_{t, 0}\right) \\
& =\mathrm{E}\left(R V_{t}^{\text {(all })} \mid \Im_{t, 0}\right)+2 \mathrm{E}\left(\sum_{i=0}^{n_{t}-1} \sum_{j=i+1}^{n_{t}} r_{t, i} r_{t, j} \mid \Im_{t, 0}\right) .
\end{aligned}
$$

If the intraday returns are uncorrelated, then

$$
\mathrm{E}\left(r_{t}^{2} \mid \mathfrak{\Im}_{t, 0}\right)=\mathrm{E}\left(R V_{t}^{\text {(all) }} \mid \mathfrak{\Im}_{t, 0}\right)=h_{t} .
$$

As a result, two unbiased estimators for the average day- $t$ return variance exist, namely, the squared day- $t$ return and the realized variance as in (1). 
However, it can be shown that

$$
\mathrm{V}\left(R V_{t}^{(\text {all })} \mid \mathfrak{\Im}_{t, 0}\right)=\frac{2}{n_{t}} \sum_{i=0}^{n_{t}} \frac{h_{t, i}^{2}}{n_{t}}<\frac{2}{n_{t}}\left(\sum_{i=0}^{n_{t}} \frac{h_{t, i}}{\sqrt{n_{t}}}\right)^{2}=\mathrm{V}\left(r_{t}^{2} \mid \mathfrak{\Im}_{t, 0}\right),
$$

as

$$
\mathrm{E}\left[\left(\sum_{i=1}^{n_{t}} h_{t, i} \eta_{t, i}^{2}\right)^{2} \mid \mathfrak{\Im}_{t, 0}\right]=\frac{3}{n_{t}^{2}} \sum_{i=0}^{n_{t}} h_{t, i}^{2}+\frac{2}{n_{t}^{2}} \sum_{i=1}^{n_{t}-1} \sum_{j=i+1}^{n_{t}} h_{t, i} h_{t, j}
$$

In short, the average daily returns variance can be estimated more accurately by summing the squared intraday returns rather than calculating the squared daily return. Moreover, when returns are observed at any arbitrary frequency, it is possible to estimate the average daily variance free of measurement error as

$$
\lim _{n_{t} \rightarrow \infty} \mathrm{V}\left(R V_{t}^{(\text {all })} \mid \Im_{t, 0}\right)=0 .
$$

The only requirement on the dynamics of the intraday return variance for the above to hold is that

$$
\sum_{i=1}^{n_{t}} h_{t, i}^{2} \propto n_{t}^{1+c}
$$

where $0 \leq c<1$. This result motivates a number of empirical articles, such as Andersen and Bollerslev (1997, 1998), Andersen et al. (1999), and Martens (2001, 2002), among others.

The theoretical foundations of the results described in this section are derived from a continuous time framework that is based on the theory of quadratic variations. Section 2.2 describes the continuous time approach without microstructure noise, whereas the effects of noise are considered in Section 2.3.

\subsection{A Continuous Time Model with No Microstructure Noise}

\subsubsection{Basic Setup}

Suppose that, along day $t$, the logarithmic prices of a given asset follow a continuous time diffusion process, as follows:

$$
d p(t+\tau)=\mu(t+\tau) d \tau+\sigma(t+\tau) d W(t+\tau), \quad 0 \leq \tau \leq 1, \quad t=1,2, \ldots,
$$

where $p(t+\tau)$ is the logarithmic price at time $t+\tau, \mu(t+\tau)$ is the drift component, $\sigma(t+\tau)$ is the instantaneous volatility (or standard deviation), 
and $W(t+\tau)$ is a standard Brownian motion. In addition, suppose also that $\sigma(t+\tau)$ is orthogonal to $W(t+\tau)$, such that there is no leverage effect.

Andersen et al. (2003) and Barndorff-Nielsen and Shephard (2002) showed that daily returns, defined as $r_{t}=p(t)-p(t-1)$, are Gaussian conditionally on $\mathfrak{I}_{t} \equiv \Im\{\mu(t+\tau-1), \sigma(t+\tau-1)\}_{\tau=0}^{\tau=1}$, the $\sigma$-algebra (information set) generated by the sample paths of $\mu(t+\tau-1)$ and $\sigma(t+\tau-1), 0 \leq \tau \leq 1$, such that

$$
r_{t} \mid \mathfrak{s}_{t} \sim N\left(\int_{0}^{1} \mu(t+\tau-1) d \tau, \int_{0}^{1} \sigma^{2}(t+\tau-1) d \tau,\right) .
$$

The term $I V_{t}=\int_{0}^{1} \sigma^{2}(t+\tau-1) d \tau$ is known as the integrated variance, which is a measure of the day- $t$ ex post volatility. The integrated variance is typically the object of interest as a measure of the true daily volatility.

\subsubsection{Different Sampling Schemes}

In practice, prices are observed at discrete and irregularly spaced intervals. In this sense, there are many ways in which one can sample the data. As in previous sections, suppose that in a given day $t$, we partition the interval $[0,1]$ in $n_{t}$ subintervals and define the grid of observation times as $\Lambda_{t}=\left\{\tau_{0}, \ldots, \tau_{n_{t}}\right\}$, where $0=\tau_{0}<\tau_{2}<\cdots<\tau_{n_{t}}=1$. The length of the $i$ th subinterval is given by $\delta_{i, n_{t}}=\tau_{i}-\tau_{i-1}$. It is assumed that the length of each subinterval shrinks to zero as the number of intraday observations increases. The integrated variance over each of the subintervals is defined as

$$
I V_{i, t}=\int_{\tau_{i-1}}^{\tau_{i}} \sigma^{2}(t+\tau-1) d \tau
$$

There are several sampling schemes that can be used, as follows:

(i) The most widely used sampling scheme is calendar time sampling (CTS), where the intervals are equidistant in calendar time, that is, $\delta_{i, n_{t}}=$ $\frac{1}{n_{t}}$ for all $i$. For example, the prices may be sampled every 5 or 15 minutes. As the intraday data are irregularly spaced, in most cases calendar time sampled data must be constructed artificially (see Andersen and Bollerslev, 1997; Dacorogna et al., 2001; Wasserfallen and Zimmermann, 1985). Hansen and Lunde (2006b) showed that the previous tick method is a sensible way to sample prices in calendar time. For example, during a five-minute interval, we may observe several prices, in which case the previous tick method takes the first observation as the sampled price.

(ii) Another sampling alternative is transaction time sampling (TrTS), where prices are recorded every $m$ th transaction. 
(iii) The third sampling scheme is known as business time sampling (BTS), where the sampling times are chosen such that $I V_{i, t}=\frac{I V_{t}}{n_{t}}$.

(iv) The last sampling alternative is called tick time sampling (TkTS), where prices are recorded at every price change.

An important difference among these distinct sampling schemes is that the observation times in BTS are latent, whereas in CTS, TrTS, and TkTs they are observed. The effects of different sampling schemes on the estimation of the integrated variance will be discussed in Section 3.3.

\subsubsection{The Distribution of $R V$}

Andersen et al. (2003) showed, using a seminal result in semimartingale process theory, that the realized variance using all data available, as defined in equation (1), is a consistent estimator of the integrated variance when there is no microstructure noise, such that

$$
R V_{t}^{(\text {all })} \stackrel{p}{\longrightarrow} I V_{t} .
$$

From the results in Jacod and Protter (1998), Barndorff-Nielsen and Shephard (2002) derived the asymptotic distribution of the realized variance as

$$
n_{t}^{1 / 2} \frac{1}{\sqrt{2 I Q_{t}}}\left(R V_{t}^{(\text {all })}-I V_{t}\right) \stackrel{d}{\longrightarrow} N(0,1),
$$

where the integrated quarticity, $I Q_{t}$, is defined as

$$
I Q_{t}=\int_{0}^{1} \sigma^{4}(t+\tau-1) d \tau .
$$

Bandi and Russell (2005a) gave an alternative simple proof of the above result.

Furthermore, under the assumption of no microstructure noise, Barndorff-Nielsen and Shephard (2002) showed that the integrated quarticity is consistently estimated by the realized quarticity, which is defined as

$$
R Q^{\text {(all) }}=\frac{n_{t}}{3} \sum_{i=0}^{n_{t}} r_{t, i}^{4},
$$

and

$$
n_{t}^{1 / 2} \frac{1}{\sqrt{\frac{2}{3} R Q_{t}^{(\text {all })}}}\left(R V_{t}^{\text {(all) }}-I V_{t}\right) \stackrel{d}{\longrightarrow} N(0,1),
$$


Barndorff-Nielsen and Shephard (2005b), Meddahi (2002), Gonçalves and Meddahi (2005), and Nielsen and Frederiksen (2006) studied the finite sample behavior of the limit theory given in (3). The main conclusion is that (3) is poorly sized, but

$$
n_{t}^{1 / 2} \frac{1}{\sqrt{\frac{2}{3} \frac{R Q_{t}^{(\text {all })}}{\left(R V_{t}^{(\text {all })}\right)^{2}}}}\left[\log \left(R V_{t}^{(\text {all })}\right)-\log \left(I V_{t}\right)\right] \stackrel{d}{\longrightarrow} N(0,1),
$$

performs quite well.

Gonçalves and Meddahi (2005) analyzed how the bootstrap may improve the limiting theory discussed above. The authors concluded that it is possible to design bootstraps which provide significant improvements over the limiting theory in (3). They also showed that the usual Edgeworth expansions, which justify the order improvement associated with the bootstrap, are not reliable guides to the finite sample behavior of the statistics. However, in cases where the computational burden imposed by the bootstrap is high, Gonçalves and Meddahi (2008) showed that using Edgeworth expansions is superior to using the limiting theory in (3).

\subsection{The Effects of Microstructure Noise}

In this section we discuss the effects of the presence of microstructure noise in the estimation of the integrated variance. Market microstructure noise has many sources, including the discreteness of the price (see Harris, 1990, 1991), and properties of the trading mechanism, as in Black (1976) and Amihud and Mendelson (1987). For additional references to this literature, see O’Hara (1995), Madhavan (2000), Hasbrouck (2004), and Biais et al. (2005).

As in Section 2.1, consider the grid of observation times, $\Lambda_{t}=$ $\left\{\tau_{0}, \ldots, \tau_{n_{t}}\right\}$. Using similar notation as in Zhang et al. (2005), set $p_{t, i} \equiv$ $p\left(t+\tau_{i}\right)$. Suppose also that the logarithmic prices are observed with noise, that is,

$$
p_{t, i}=p_{t, i}^{*}+\varepsilon_{t, i}
$$

where $p_{t, i}^{*}$ is the latent efficient (or true) price process and $\varepsilon_{t, i}$ is the microstructure noise.

It follows that

$$
r_{t, i}=r_{t, i}^{*}+\varepsilon_{t, i}-\varepsilon_{t, i-1}=r_{t, i}^{*}+v_{t, i}
$$


where $r_{t, i}^{*}=p_{t, i}^{*}-p_{t, i-1}^{*}$ is the efficient return. It is clear that $r_{t, i}$ is an autocorrelated process, so that $R V_{t}^{(\text {all })}$ will be a biased estimator of the latent true daily volatility, as discussed in Section 2.1. Furthermore, as

$$
R V_{t}^{(\mathrm{all})}=\sum_{i=1}^{n_{t}}\left(r_{t, i}^{*}\right)^{2}+2 \sum_{i=1}^{n_{t}} r_{t, i}^{*} v_{t, i}+\sum_{i=1}^{n_{t}} v_{t, i}^{2}
$$

it is straightforward to show that, conditionally on the efficient returns,

$$
\mathrm{E}\left(R V_{t}^{(\text {all })} \mid r^{*}\right)=R V_{t}^{*(\text { all })}+2 n_{t} \mathrm{E}\left(\varepsilon_{t, i}^{2}\right)
$$

such that $R V_{t}^{(\text {all })}$ is also a biased estimator of the integrated variance.

As in Bandi and Russell (2005a), consider the following assumption regarding the noise structure.

\section{Assumption 1 (Noise Structure).}

(a) The microstructure noise, $\varepsilon_{t, i}$, has zero mean and is a covariance stationary stochastic process.

(b) The variance of $v_{t, i}=\varepsilon_{t, i}-\varepsilon_{t, i-1}$ is $O(1)$.

Under Assumption 1, Bandi and Russell (2005a) showed that

$$
R V_{t}^{(\text {all })} \stackrel{\text { a.s. }}{\longrightarrow} \infty \quad \text { as } n_{t} \rightarrow \infty
$$

Furthermore, consider the following assumption.

Assumption 2 (IID Noise Structure).

(a) The microstructure noise, $\varepsilon_{t, i}$, has zero mean and is an independent and identically distributed random variable.

(b) The noise is independent of the price process.

(c) The variance of $v_{t, i}=\varepsilon_{t, i}-\varepsilon_{t, i-1}$ is $O(1)$.

Under Assumption 2, it was shown in Zhang et al. (2005) that

$$
n_{t}^{-1 / 2}\left[R V_{t}^{(\mathrm{all})}-I V_{t}-2 n_{t} \mathrm{E}\left(\varepsilon_{t, i}^{2}\right)\right] \stackrel{d}{\longrightarrow} 2\left[\mathrm{E}\left(\varepsilon_{t, i}^{4}\right)\right]^{1 / 2} N(0,1) .
$$

In practical applications, even sampling at the highest available frequency, the number of intraday observations is finite and the price records are 
discrete. This introduces a bias due to discretization, such that

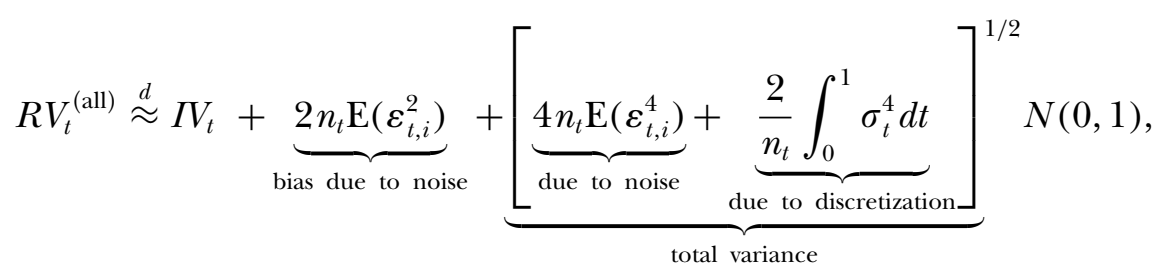

where “ $\stackrel{d}{\approx}$ " means that, when multiplied by a suitable factor, the convergence is in distribution.

Recently, Zhang (2006a) and Ait-Sahalia et al. (2006), considered the case where the noise is not IID, such that Assumption 2 is modified as follows.

Assumption 3 (Dependent Noise Structure).

(a) The microstructure noise, $\varepsilon_{t, i}$, has a zero mean, stationary, and strong mixing stochastic process, with the mixing coefficients decaying exponentially. In addition, $\mathrm{E}\left[\left(\varepsilon_{t, i}\right)^{4+\kappa}\right]<\infty$, for some $\kappa>0$.

(b) The noise is independent of the price process.

(c) The variance of $v_{t, i}=\varepsilon_{t, i}-\varepsilon_{t, i-1}$ is $O(1)$.

Under Assumption 3, Zhang (2006a) and Ait-Sahalia et al. (2006) showed that

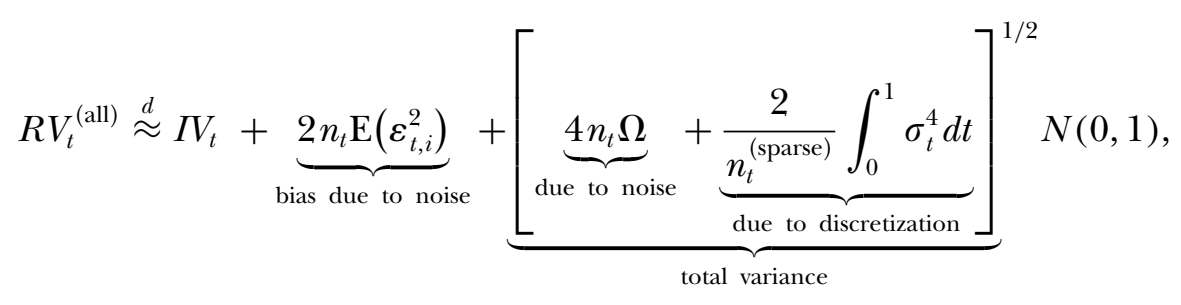

where

$$
\Omega=\mathrm{V}\left[\left(\varepsilon_{t, 1}-\varepsilon_{t, 0}\right)^{2}\right]+2 \sum_{i=1}^{\infty} \operatorname{Cov}\left[\left(\varepsilon_{t, 1}-\varepsilon_{t, 0}\right)^{2},\left(\varepsilon_{t, i+1}-\varepsilon_{t, i}\right)^{2}\right] .
$$

The most important fact about the last result is that, for large $n_{t}$, the realized variance (1) may have no connection to the true returns. On the contrary, $R V_{t}^{\text {(all) }}$ diverges to infinity linearly in $n_{t}$. In addition, Bandi and Russell (2005a) and Zhang et al. (2005) showed that, scaled by $\left(2 n_{t}\right)^{-1}$, the realized variance estimates the variance of the microstructure noise 
consistently, such that

$$
\frac{1}{2 n_{t}} R V_{t}^{(\mathrm{all})} \stackrel{p}{\longrightarrow} \mathrm{E}\left(\varepsilon_{t, i}^{2}\right) .
$$

As advocated in Andersen et al. (2000a, 2001a, 2003), one possible solution to the microstructure bias is to sample the returns at arbitrarily selected lower frequencies, such as every 5 or 15 minutes, instead of at every tick. This procedure is called sparse sampling. However, Zhang et al. (2005) showed that this is not an adequate solution to the problem. First, define a new grid $\Lambda_{t}^{\text {(sparse) }}$, with $n_{t}^{\text {(sparse) }}$ sparsely equidistant sampled observation times. Clearly, $\Lambda_{t}^{\text {(sparse) }}$ is a subgrid of $\Lambda_{t}$. Set

$$
R V_{t}^{\text {(sparse) }}=\sum_{i=1}^{n_{t}^{\text {(sparse })}} r_{t, i}^{2}
$$

Based on the results of Rootzen (1980), Jacod and Protter (1998), Barndorff-Nielsen and Shephard (2002), Mykland and Zhang (2006), Zhang et al. (2005), Zhang (2006a), and Ait-Sahalia et al. (2006) showed that the bias due to noise is given by $2 n_{t}^{(\text {sparse })} \mathrm{E}\left(\varepsilon_{t, i}^{2}\right)$ and that, under Assumptions 2 or 3,

$$
\begin{aligned}
& R V_{t}^{\text {(sparse) }} \stackrel{d}{\approx} I V_{t}+\underbrace{2 n_{t}^{\text {(sparse) }} \mathrm{E}\left(\varepsilon_{t, i}^{2}\right)}_{\text {bias due to noise }}
\end{aligned}
$$

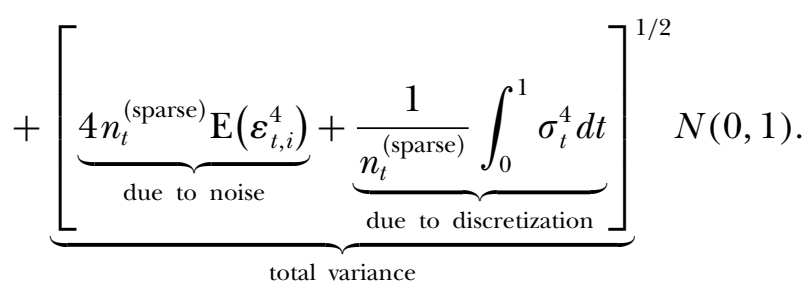

Although the bias is reduced when $n_{t}^{\text {(sparse) }}<n_{t}$, the variance is increased due to discretization, leading to the well-known bias-variance trade-off. Even though choosing the sampling frequency on the basis of the finite sample mean-squared-error (MSE) is optimal in the case of realized variance, alternative estimators (discussed below) have been proposed that have the potential, when appropriately implemented, to outperform the classical realized variance estimator. 


\section{MICROSTRUCTURE NOISE AND RV ESTIMATION}

\subsection{Selection of Frequency and Sparse Sampling}

Under Assumption 2, Bandi and Russell (2005a,b) and Zhang et al. (2005) proposed a method of selecting the optimal sampling frequency based on the minimization of the MSE, as follows:

$$
\begin{aligned}
\operatorname{MSE}\left(n_{t}^{\text {(sparse) }}\right)= & 2 n_{t}^{\text {(sparse) }} \mathrm{E}\left(\varepsilon_{t, i}^{2}\right)+4 n_{t}^{\text {(sparse) }} \mathrm{E}\left(\varepsilon_{t, i}^{4}\right) \\
& +\left[8 R V_{t}^{\text {(sparse) }} \mathrm{E}\left(\varepsilon_{t, i}^{2}\right)-2 V\left(\varepsilon_{t, i}^{2}\right)\right]+\frac{2}{n_{t}^{\text {(sparse) }}} I Q^{\text {(sparse) }} .
\end{aligned}
$$

Thus, the optimal sampling frequency may be approximated by

$$
n_{t}^{*} \approx\left\{\frac{I Q_{t}}{4\left[E\left(\varepsilon_{t, i}^{2}\right)\right]^{2}}\right\}^{1 / 3} .
$$

Bandi and Russell (2005a, 2006b) considered equidistant sampling intervals, whereas Zhang et al. (2005) provided a more general formula for irregularly spaced data. However, Bandi and Russell (2005a) also considered optimal sampling with dependent noise, optimal sampling with bias-corrected realized variance estimates, and optimal sampling with prefiltered data.

As discussed previously, $E\left(\varepsilon_{t, i}^{2}\right)$ may be consistently estimated by $\frac{1}{2 n_{t}} R V_{t}^{(\text {all) }}$; see Equation (8). Consistent estimation notwithstanding, an important point that must be emphasized is that the integrated quarticity is not known, and hence must be estimated. However, the realized quarticity, as given in Equation (5), is not consistent in the presence of microstructure noise. Bandi and Russell (2005a, 2006b) adopted the solution of computing (14) using a sparse set of observations, namely one that is sampled every 15 minutes. The authors showed through simulation that such sparse sampling did not seem to have a harmful effect on the selection of the optimal frequency. Zhang et al. (2005) developed an alternative solution for estimating the integrated quarticity. Nevertheless, the development of a robust integrated quarticity estimator appears to be an important topic for future research.

\subsection{Bias Correction and Consistent Estimation}

\subsubsection{Subsampling}

Zhang et al. (2005) proposed a subsampling method in order to estimate the integrated variance consistently in the presence of 
microstructure noise. ${ }^{3}$ The main idea is to explore the fact that, for example, ten-minute returns starting at 9:30 could be measured using the intervals 9:30-9:40, 9:40-9:50, ., 9:31-9:41, 9:41-9:51, and so on. Formally, suppose that the full grid, $\Lambda_{t}=\left\{\tau_{0}, \ldots, \tau_{n_{t}}\right\}$, is partitioned into $K$ nonoverlapping subgrids, $\Lambda_{t}^{(k)}, k=1, \ldots, K$, such that

$$
\Lambda_{t}=\bigcup_{k=1}^{K} \Lambda_{t}^{(k)}, \quad \text { where } \Lambda_{t}^{(k)} \cap \Lambda_{t}^{(j)}=\phi \text { when } k \neq j .
$$

Set $n_{t}^{(k)}$ as the number of observations in each subgrid, and define the RV for grid $k$ as

$$
R V_{t}^{(k)}=\sum_{i=1}^{n_{t}^{(k)}} r_{t, i}^{2}
$$

The proposal of Zhang et al. (2005) is to use the following estimator for the daily RV:

$$
R V_{t}^{\text {(ZMA) }}=\frac{1}{K} \sum_{k=1}^{K} R V_{t}^{(k)}-\frac{\bar{n}_{t}}{n_{t}} R V_{t}^{(\text {all })},
$$

where $n_{t}$ is the number of observations in the full grid, and

$$
\bar{n}_{t}=\frac{1}{K} \sum_{k=1}^{K} n_{t}^{(k)}=\frac{n_{t}-K+1}{K} .
$$

The estimator in (12) is called the Two Time Scales Estimator (TTSE) of the integrated variance. Zhang et al. (2005) showed that, under Assumption 2,

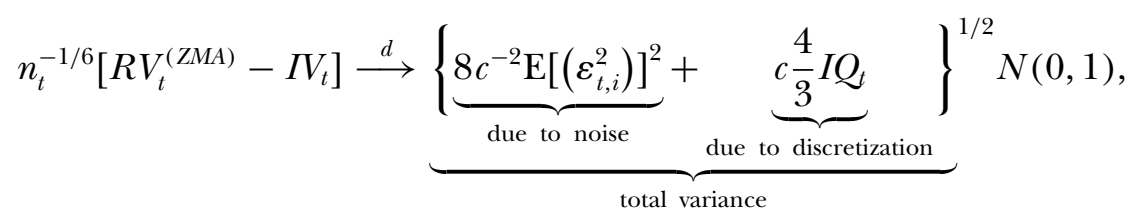

where, in the case of equidistant observations,

$$
c=\left\{\frac{1}{12 \mathrm{E}\left[\left(\varepsilon_{t, i}^{2}\right)\right]^{2}} I Q_{t}\right\}^{-1 / 3} .
$$

\footnotetext{
${ }^{3}$ See also Ait-Sahalia et al. (2005) for a consistent maximum likelihood estimation of the constant variance of a diffusion process with microstructure noise.
} 
In Aït-Sahalia et al. (2006), a small sample refinement to the estimator in (12) is proposed. The final estimator becomes

$$
R V_{t}^{(\mathrm{ZMA}, \mathrm{adj})}=\left(1-\frac{\bar{n}_{t}}{n_{t}}\right)^{-1} R V_{t}^{(\mathrm{ZMA})}
$$

Both of the estimators in (12) and (13) are derived under Assumption 2 (IID noise). In order to take into account possibly dependent noise, Zhang (2006a) and Aït-Sahalia et al. (2006) proposed an alternative estimator that is also based on the two time scales idea. All the results are derived under Assumption 3 (non-IID noise).

First, the authors defined the average lag $J \mathrm{RV}, R V_{t, J}^{(\mathrm{AL})}$, which is given by

$$
R V_{t, J}^{(\mathrm{AL})}=\frac{1}{J} \sum_{i=0}^{n_{t}-J}\left(r_{t, i+J}-r_{t, i}\right)^{2}
$$

Then the authors proposed a generalization of the TSSE derived in Zhang et al. (2005), which has the form

$$
R V_{t}^{(\mathrm{AMZ})}=R V_{t, K}^{(\mathrm{AL})}-\frac{\bar{n}_{t}^{(K)}}{\bar{n}_{t}^{(J)}} R V_{t, J}^{(\mathrm{AL})}
$$

where $1 \leq J \leq K \leq n_{t}, K=o\left(n_{t}\right), \bar{n}_{t}^{(K)}=\frac{\left(n_{t}-K+1\right)}{K}$ and $\bar{n}_{t}^{(J)}=\frac{\left(n_{t}-J+1\right)}{J}$. Note that (14) becomes the TTSE in Zhang et al. (2005) when $J=1$ and $K \rightarrow \infty$ as $n_{t} \rightarrow \infty$. A small sample correction is given by

$$
R V_{t}^{(\mathrm{AMZ}, \mathrm{adj})}=\left(1-\frac{\bar{n}_{t}^{(K)}}{\bar{n}_{t}^{(J)}}\right)^{-1} R V_{t}^{(\mathrm{AMZ})} .
$$

Zhang (2006a) and Aït-Sahalia et al. (2006) showed that

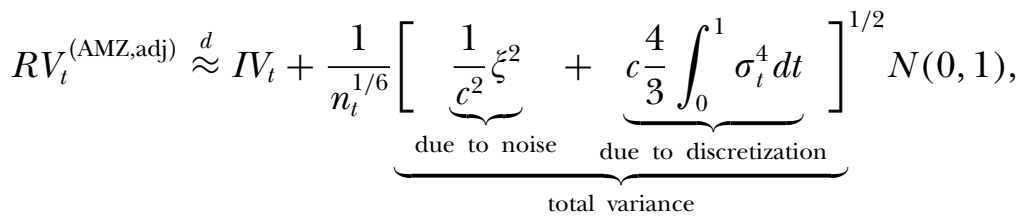

where $c$ is a constant and

$$
\xi^{2}=16 V\left(\varepsilon_{t, i}\right)^{2}+32 \sum_{i=1}^{\infty} \operatorname{Cov}\left(\varepsilon_{t, 0}, \varepsilon_{t, i}\right)^{2}
$$




\subsubsection{Kernel-Based Estimators}

Consistently estimating the quadratic variation under the presence of microstructure noise is, in a sense, similar to the well-known autocorrelation corrections that are frequently used in the time-series literature to estimate the long run variances and covariances of stationary stochastic processes (see, for example, Andrews, 1991; Newey and West, 1987). Consequently, it is natural to adapt similar techniques for the present case. For example, Hansen and Lunde (2004, 2006a) considered the following simple kernel-based estimator:

$$
R V_{t}^{(\mathrm{HL})}=R V_{t}^{(\mathrm{all})}+2 \sum_{h=1}^{H} \frac{n_{t}}{n_{t}-h} \hat{\gamma}_{h},
$$

where

$$
\hat{\gamma}_{h}=\frac{n_{t}}{n_{t}-h} \sum_{j=1}^{n_{t}-h} r_{t, j} r_{j+h} .
$$

Zhou (1996) was the first to consider the use of kernel methods to deal with the problem of microstructure noise in high-frequency data. For the case of independent noise, Zhou proposed (17) with $H=1$. Hansen and Lunde (2006b) examined the properties of Zhou's estimator and showed that, although unbiased under Assumption 2, the estimator is not consistent. However, Hansen and Lunde (2006b) advocated that, while inconsistent, Zhou's kernel method is able to uncover several properties of the microstructure noise, and concluded that the noise:

(i) Is correlated with the efficient price;

(ii) Is time dependent;

(iii) Is quite small in the DJIA stocks; and

(iv) Has properties that have changed substantially over time.

Their results are robust to both CTS and TrTS. Moreover, selecting higher values for $H$ does not solve the consistency problem. However, the estimator in (17) is unbiased by an upwards scaling of the empirical autocovariances. The $h$ th autocovariance is scaled by $\frac{n_{t}}{n_{t}-h}$ to compensate for the "missing" autocovariance terms.

The upward scaling has the drawback that it increases the variance of the estimator. For this reason, Hansen and Lunde (2005b) consider the Bartlett kernel and define the estimator

$$
R V_{t}^{(\mathrm{HL}, \mathrm{Bartlett})}=R V_{t}^{(\text {all })}+2 \sum_{h=1}^{H}\left(1-\frac{h}{H+1}\right) \hat{\gamma}_{h},
$$


where $H$ is determined as $H=\left\lceil\left(\frac{4 n_{t}}{100}\right)^{2 / 9}\right\rceil$, and $\hat{\gamma}_{h}$ is defined as in (18). However, the estimator (19) is also inconsistent.

Recently, Barndorff-Nielsen et al. (2006a) proposed the flat-top kernelbased estimator ${ }^{4}$

$$
R V_{t}^{(\mathrm{BHLS})}=R V_{t}^{(\mathrm{all})}+\sum_{h=1}^{H} k\left(\frac{h-1}{H}\right)\left(\hat{\gamma}_{h}+\hat{\gamma}_{-h}\right),
$$

where $k(x)$ for $x \in[0,1]$ is a nonstochastic weight function such that $k(0)=1$ and $k(1)=0$. The authors made several contributions to the literature by:

(i) Proving that the statement that all kernel based RV estimators were inconsistent is wrong and proposed several consistent kernel-based estimators;

(ii) Designing a kernel that has a smaller variance than the multiscale estimator;

(iii) Proposing an estimator for data with endogenously spaced observations, such as that in databases on transactions; and

(iv) Considering the case where the microstructure noise is endogenous.

Barndorff-Nielsen et al. (2006a) showed that, if $H=c n_{t}^{2 / 3}$, then the resulting estimator is asymptotically mixed Gaussian, converging at rate $n_{t}^{1 / 6}$. The constant, $c$, can be optimally chosen as a function of the kernel $k(x)$. For example, the value of $c$ that minimizes the variance of the estimator is given by

$$
c=\left\{\frac{2\left[k^{\prime}(0)^{2}+k^{\prime}(1)^{2}\right]}{\int_{0}^{1} k(x)^{2} d x}\right\}^{1 / 3} \frac{\left[\mathrm{E}\left(\varepsilon_{t, i}^{2}\right)\right]^{2 / 3}}{I Q^{3}} .
$$

Barndorff-Nielsen et al. (2006a) also compared three different kernels:

(i) Bartlett where $k(x)=1-x$;

(ii) 2nd order where $k(x)=1-2 x-x^{2}$; and

(iii) Epanechnikov where $k(x)=1-x^{2}$.

Their findings are summarized as follows: the Bartlett kernel has the same asymptotic distribution as the TTSE of Zhang et al. (2005) and is more efficient than the Epanechnikov alternative, but is less efficient than the 2nd order kernel.

Moreover, if $k^{\prime}(0)=0$ and $k^{\prime}(1)=0$, then setting $H=c n_{t}^{1 / 2}$, the asymptotic distribution of the estimator is mixed normal with convergence

\footnotetext{
${ }^{4}$ See also Sun (2006) for a similar class of unbiased and consistent estimators.
} 
rate equal to $n_{t}^{1 / 4}$. Barndorff-Nielsen et al. (2006a) discussed the choice of the constant $c$ in a simplified framework where the variance of the efficient price is held constant. In their article, the authors compared eight different kernels satisfying $k^{\prime}(0)=0$ and $k^{\prime}(1)=0$. The cubic kernel, where $k(x)=1-3 x^{2}+2 x^{3}$, has the same asymptotic distribution as the multiscale estimator of Ait-Sahalia et al. (2006) and Zhang (2006a). The Tukey-Hanning kernel, where $k(x)=\frac{\left[1-\cos \pi(1-x)^{2}\right]}{2}$, seems to be the best option in terms of efficiency.

Barndorff-Nielsen et al. (2006a) also showed that the findings above are robust to endogenous ${ }^{5}$ and/or dependent noise, and endogenously spaced observations, as in tick data databases. They also provided Monte Carlo evidence in favor of their estimators in finite samples.

\subsubsection{Filters}

In the early days of modelling RV, another common alternative to attenuate the effects of the microstructure noise was to pre-filter the intraday returns. For example, in Bollen and Inder (2002), an autoregressive (AR) filter was used, while a moving average (MA) filter was considered in Ebens (1999), Maheu and McCurdy (2002), and Andersen et al. (2001a). More recently, Hansen et al. (2008), showed that the MA(1) structure considered in Ebens (1999) and Andersen et al. (2001a) is well specified when the market microstructure noise is IID. Moreover, when correcting the estimator by a scaling factor, it becomes a consistent estimator of the integrated variance (see Hansen et al., 2008 for further details).

\subsubsection{Alternative Estimator}

Recently, Large (2006) proposed an interesting estimator of quadratic variation which controls for microstructure effects when the best quotes change by jumping the minimum price tick. The estimator compares the number of alternations, where quotes jump back to their previous price, with the number of other jumps. If the alternations are uncorrelated, the estimator is consistent in a limit theory where jumps are very frequent and small.

\subsection{The Effects of the Sampling Scheme}

As discussed in Section 2.2, there are several ways of sampling intraday returns, and the choice of sampling scheme can have a strong influence on the statistical properties of the realized variance. Most of the work

\footnotetext{
${ }^{5}$ The authors considered a simple form of dependence between the noise and the efficient price process.
} 
discussed previously did not directly address the issue of choosing the sampling scheme. The first to contribute in that direction was Oomen (2005), who examined the following sampling alternatives: (i) calendar time sampling, (ii) transaction time sampling, (iii) tick time sampling, and (iv) business time sampling.

Compared with the standard literature, Oomen (2006) proposed a pure jump process for the high frequency-prices, which allows for the analysis of the following sampling schemes: calendar time, business time, and transaction time sampling. The price process is formed by an efficient martingale component, which is described as a compound Poisson process plus the market microstructure noise that is allowed to have an $\operatorname{MA}(q)$ structure. Thus, the asset price is modeled as the accumulation of a finite number of jumps, each of which represents a transaction return, with the Poisson process counting the number of transactions. The optimal sampling frequency is derived to minimize the MSE, which is influenced by the number of trades and the noise level. It was shown that, as in the case of the diffusion-based models, the realized variance is a biased estimator of the jump analogue of the integrated variance when microstructure noise is present. However, as distinct from previous results, the bias does not diverge to infinity as the sample frequency increases. Concerning the sampling schemes, the main conclusion is that transaction time sampling is generally superior to the common practice of calendar time sampling, as the former leads to a lower MSE of the realized variance. This effect is pronounced, especially when the trading intensity pattern is volatile.

Oomen (2005) extended the model in Oomen (2006) in order to study the effects of the first-order bias correction on different sampling schemes. His correction is in line with those proposed by Zhou (1996) and Hansen and Lunde (2006b). However, the present results were derived under a pure jump process with IID noise instead of a diffusion-based model. Oomen (2005) showed that the bias correction significantly reduces the bias caused by microstructure effects, and is more effective in transaction time than in calendar time. Moreover, for an equal number of sampled returns, bias-corrected estimators attains a lower MSE when the returns are sampled regularly spaced on a transaction time scale rather than on a calendar time scale.

Griffin and Oomen (2008) introduced a new model for transaction patterns in order to distinguish the effects of tick time and transaction time sampling. The main findings of the article are:

(i) Tick time sampling is equivalent to transaction time sampling for high levels of microstructure noise, and is superior for low levels of microstructure noise; and 
(ii) When the first-order bias corrected estimator of Zhou (1996) and Hansen and Lunde (2006b) is considered, transaction time sampling is always preferred.

\subsection{Comparison of Techniques}

As shown in the previous section, there are many different possibilities for dealing with the problem of microstructure noise in the estimation of the integrated variance. Table 1 compares the different methods to estimate the integrated variance according to their asymptotic properties. The aim of the table is not to rank different methods but to summarize the main large-sample properties of each of them. It is important to mention that, although there are many unbiased estimators, only four are consistent. The first consistent estimator is the TTSE of Zhang et al. (2005) and Ait-Sahalia et al. (2005). The order of convergence of the TTSE in Zhang et al. (2005) is $n_{t}^{1 / 6}$, while that in Ait-Sahalia et al. (2005) is $n_{t}^{1 / 4}$. Hansen and Lunde (2006b) noted that a subsampling version of the kernel estimator of Zhou (1996) is also a consistent estimator and a formal proof was given in Barndorff-Nielsen et al. (2006b). BarndorffNielsen et al. (2006a) derived the realized kernel consistent estimator that generalizes the previous results in Hansen and Lunde (2006b), and which is also of order $n_{t}^{1 / 4}$. In a companion article, Barndorff-Nielsen et al. (2006b) showed the equivalence between their estimators and those in Zhang et al. (2005) and Aït-Sahalia et al. (2005). The third consistent estimator is the modified MA filter of Hansen et al. (2008), which is also of order $n_{t}^{1 / 4}$. However, these estimators differ regarding the hypothesis about the microstructure noise and sampling schemes. The fourth one is the alternation estimator of Large (2006).

The preceding discussion notwithstanding, it is important to note that, while not being consistent, the kernel estimators discussed in Hansen and Lunde (2006b) are important tools for uncovering, if only partially, several properties of the microstructure noise.

From the practical perspective, an important issue regarding the properties of an estimator relate to finite sample or asymptotic properties. Although this is not straightforward to determine, we wish to provide the practitioner with some guidelines for choosing the most convenient estimator, which may be an estimator that is listed in Table 1 or may be a combination of alternatives.

In order to obtain consistent estimators, Barndorff-Nielsen et al. (2006c), Zhang et al. (2005), and Ait-Sahalia et al. (2005) required that the number of autocovariances (or subsamples) $H$ and the number of observations, $n_{t}$, to diverge to infinity as the ratio $\phi=\frac{H}{n_{t}} \rightarrow 0$. However, for a given $\phi$, the magnitude of the finite sample MSE of the estimators can be 


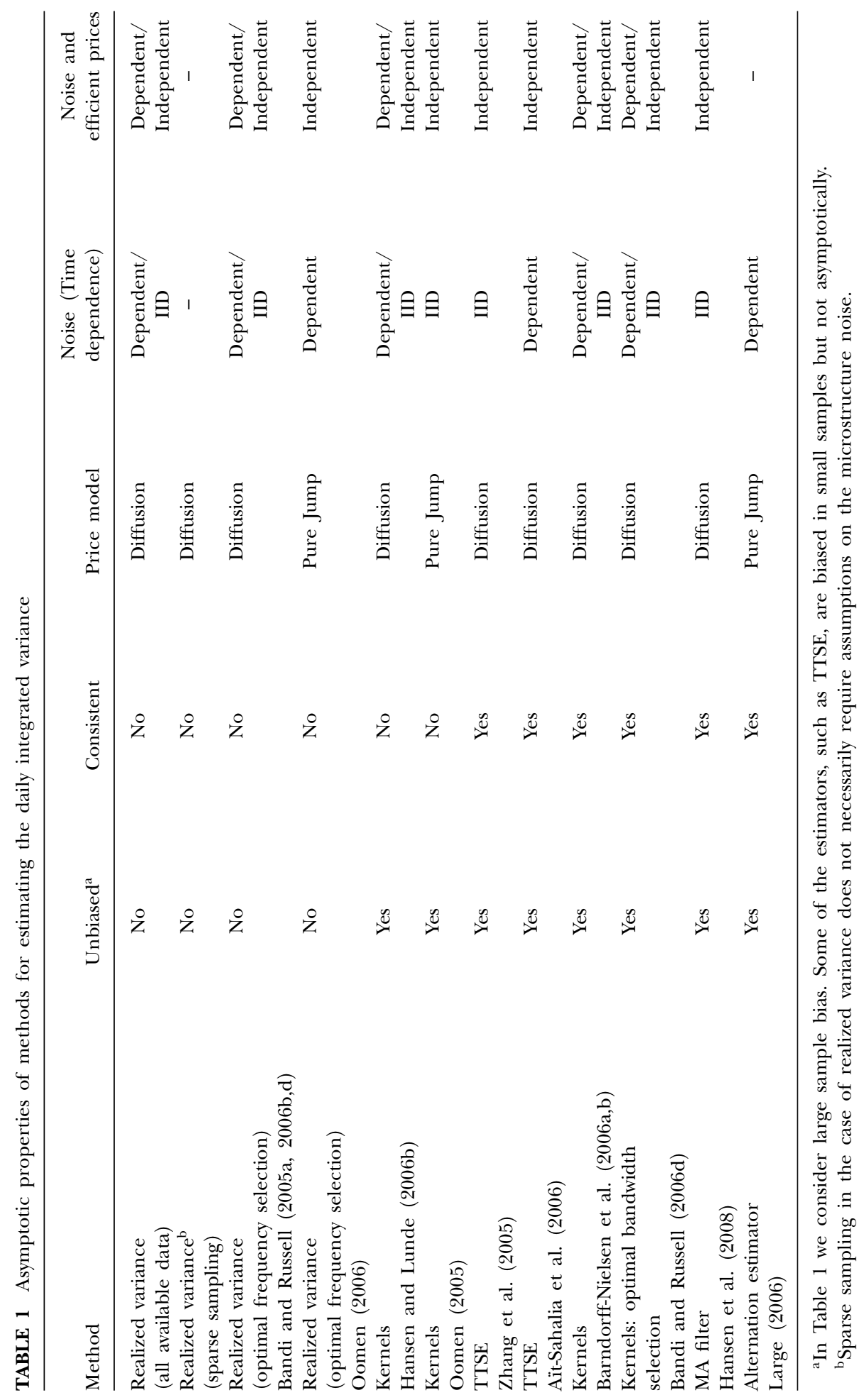


substantially different from the asymptotic approximations. Moreover, in practice, researchers are always forced to select a value for $\phi$ (see Remark 3 in Bandi and Russell, 2006c for a discussion on the importance of finite sample properties of integrated variance estimators). Bandi and Russell (2006d) undertook a detailed study of the finite sample performance of several kernel-based and subsampling estimators under Assumption 2, and showed how to select optimally the value of $\phi$ based on a finite sample MSE criterion. The authors found that for the realistic sample sizes encountered in practical applications, the asymptotic results for some of the estimators discussed above, in general, do not provide sufficient guidance for practical implementation, as they provide unsatisfactory representations of the finite sample properties of the estimators. In addition, the authors showed how to optimize the finite sample properties of these estimators, providing significant statistical and economic gains when compared with the "suboptimal" estimators. Concerning Zhang et al. (2005) estimator and the biased kernel estimators of Hansen and Lunde (2005b), their main conclusions are as follows:

(i) The finite sample MSE properties of the consistent estimator $\left(R V_{t}^{(\mathrm{ZMA})}\right)$ of Zhang et al. (2005), and of the inconsistent Bartlett kernel estimator $\left(R V_{t}^{(\mathrm{HL}, \mathrm{Bartlett})}\right)$ discussed in Hansen and Lunde $(2005 \mathrm{~b})$, are similar, and a significant component of their mean-squared error is induced by the finite sample bias.

(ii) Asymptotic methods to select the bandwidth can be suboptimal in their case, especially for biased kernel estimators. As their finite sample bias vanishes asymptotically, asymptotic methods do not take the finite sample bias into account and have a tendency to select an excessively small number of bandwidths. A small $H$ can lead to a large bias component in a finite sample.

(iii) This bias component can be reduced by choosing $H$ in order to minimize the estimator's finite sample MSE. In the case of Zhang et al. (2005) estimator and the Bartlett kernel estimator of Hansen and Lunde (2005b), the authors proposed a simple (MSE-based) rule-of-thumb to select the ratio, $\phi$, which is given by:

$$
\phi_{(\mathrm{Bartlett}, \mathrm{HL})}^{*}=\phi_{\mathrm{ZMA}}^{*}=\phi^{*} \approx\left(\frac{3}{2} \frac{\frac{R V_{t}^{(\mathrm{all})}}{n_{t}^{2}}}{I Q_{t}}\right)^{1 / 3}
$$

(iv) While the optimal finite sample MSE values of Zhang et al.'s (2005) estimator and Hansen and Lunde's (2005b) Bartlett kernel estimator are generally smaller than the optimal finite sample MSE value of the classical realized variance estimator, the gains that these useful 
estimators can provide over the classical realized variance estimator might be lost or dramatically reduced by suboptimally choosing the value of $\phi$.

Bandi and Russell (2006d) also evaluate the finite sample behavior of the consistent flat-top kernel based estimators proposed by BarndorffNielsen et al. (2006c). Although Bandi and Russell (2006d) do not provide an expression for the optimal ratio, $\phi$, in this case, they conduct a detailed simulation exercise to examine the finite sample properties of three flattop kernels, namely, the Bartlett, cubic, and modified Tukey-Hanning kernels. The optimal bandwidth is chosen by minimizing the finite sample variance of the unbiased flat-top symmetric kernels, thereby leading to finite sample MSE optimization. Their main findings are as follows:

(i) Despite having the same distribution as the subsampling estimator of Zhang et al. (2005), the flat-top Bartlett kernel estimator appears to be preferable to the former in finite samples. Furthermore, the cubic flat-top kernel, which is equivalent to the multiscale estimator, does not seem to improve on the finite sample performance of the flat-top Bartlett kernel. The flat-top Tukey-Hanning kernel performs marginally better than do the other two kernels.

(ii) The use of asymptotic criteria to select the optimal value of $H$ (namely, the number of autocovariance terms) can be more or less satisfactory depending on the choice of kernel. It was found that the asymptotic criteria are accurate when the cubic kernel is chosen.

(iii) Due to the lack of a substantial bias term and the flatness of the variance term as a function of $\phi$, the suboptimal bandwidth choices do not lead to extremely large losses.

(iv) Although the cubic flat-top kernel implies a faster rate of convergence than does the Bartlett flat-top kernel, the finite sample performance of the two estimators is almost identical.

(v) The asymptotic approximations to the finite sample dispersion of the symmetric estimators can be imprecise. A careful assessment of the accuracy of these estimators requires a closer examination of their finite sample properties.

Nielsen and Frederiksen (2006) also evaluated the finite sample accuracy of different estimators of the integrated variance under the presence of microstructure noise and possible jumps. The authors considered three estimators: the realized variance, the estimator based on Fourier series (Barucci and Reno, 2002a,b; Malliavin and Mancino, 2002), and finally, the wavelet estimator of Høg and Lunde (2003). The main conclusion of the article is that the Fourier estimator is preferable when compared to the other two and, most surprisingly, it has a slightly better 
finite sample performance (in terms of MSE) than the bias-corrected kernel-based estimators as in Hansen and Lunde (2006b).

However, one question is still open: What are the finite sample properties of the estimators discussed above under more general assumptions about the microstructure noise?

Another important way of selecting an estimator for the integrated variance is to use economic or financial measures. For example, one might decide to choose an estimator that achieves greater accuracy in forecasting Value-at-Risk thresholds in determining optimal Basel Accord capital charges. On the other hand, one might proceed, as in Fleming et al. (2001, 2003), by examining the economic benefits of different volatility measures in a dynamic portfolio allocation experiment (see also Section 5.2 for further discussion). In summary, the predictive ability of different estimators might be used as criterion to decide among different alternatives (see Remark 5 in Bandi and Russell, 2006c for a useful discussion).

\section{THE GENERAL MULTIVARIATE FRAMEWORK}

There has been growing theoretical and empirical interest in extending the results for the univariate processes discussed previously to a multivariate framework. In this context, two pioneering contributions have been made by Barndorff-Nielsen and Shephard (2004b) and Bandi and Russell (2005b). Barndorff-Nielsen and Shephard (2004b) did not consider the presence of microstructure noise, whereas the case of noise has been considered in Bandi and Russell (2005b). Section 4.1 briefly reviews the results in Barndorff-Nielsen and Shephard (2004b) and Bandi and Russell (2005b). Section 4.2 gives some references of promising recent developments in the multivariate context.

\subsection{Realized Covariance}

As in (2), suppose that, along day $t$, the logarithmic prices of a given set assets follow a continuous time diffusion process, as follows:

$$
d \mathbf{p}(t+\tau)=\boldsymbol{\mu}(t+\tau)+\boldsymbol{\Theta}(t+\tau) d \mathbf{W}(t+\tau), \quad 0 \leq \tau \leq 1, \quad t=1,2, \ldots,
$$

where $\mathbf{p}(t+\tau)$ is a vector of logarithmic prices at time $t+\tau, \boldsymbol{\mu}(t+$ $\tau)$ is the multivariate drift component, $\boldsymbol{\Theta}(t+\tau)$ is the instantaneous co-volatility matrix, and $\mathbf{W}(t+\tau)$ is the standard multivariate Brownian motion. As before, suppose also that $\boldsymbol{\Theta}(t+\tau)$ is orthogonal to $\mathbf{W}(t+\tau)$. The instantaneous covariance matrix is $\boldsymbol{\Sigma}(t+\tau)=\boldsymbol{\Theta}(t+\tau) \boldsymbol{\Theta}(t+\tau)^{\prime}$, with generic element given by $\Sigma_{(u)(s)}(t+\tau)$. 
Define the realized covariance as

$$
\mathbf{R C o v}_{t}^{(\mathrm{ALL})}=\sum_{i=1}^{n_{t}} \mathbf{r}_{i, t} \mathbf{r}_{i, t}^{\prime}
$$

Barndorff-Nielsen and Shephard (2004b) showed that

$$
n_{t}^{1 / 2}\left[\operatorname{vech}\left(\mathbf{R C o v}_{t}^{(\mathrm{ALL})}\right)-\operatorname{vech}\left(\int_{0}^{1} \boldsymbol{\Sigma}(t+\tau) d \tau\right)\right] \stackrel{d}{\longrightarrow} N\left(0, \boldsymbol{\Pi}_{t}\right),
$$

where $\Pi_{t}$ is a positive definite matrix (see Barndorff-Nielsen and Shephard, 2004b for further details).

Under the presence of microstructure noise, Bandi and Russell (2005b) showed that the realized covariation estimator given in (23) is not consistent. Bandi and Russell (2005b) proposed a method for selecting the optimal sampling frequency as a trade-off between bias and efficiency. The optimal sampling frequency is given by

$$
n_{t}^{*} \approx\left\{\frac{Q_{(u)(s) t}}{2\left[\mathrm{E}\left(\varepsilon_{(u) t, i} \varepsilon_{(s) t, i}\right)\right]^{2}}\right\}^{1 / 3}
$$

where

$$
Q_{(u)(s) t}=\int_{0}^{1}\left[\Sigma_{(u)}(t+\tau) \Sigma_{(s)}(t+\tau)+\Sigma_{(u)(s)}^{2}(t+\tau)\right] d \tau
$$

Bandi and Russell (2005b) suggest estimating (26) with a sparse sampling frequency of 15 or 20 minutes as

$$
\hat{Q}_{(u)(s) t}=n_{t}^{(\text {sparse })} \sum_{i=1}^{n_{t}^{\text {(sparse) }}} r_{(u) i, t}^{2} r_{(s) i, t}^{2}-n_{t}^{\text {(sparse) }} \sum_{i=1}^{n_{t}^{\text {(sparse) }}-1} r_{(u) i, t} r_{(s) i, t} r_{(u) i+1, t} r_{(s) i+1, t}
$$

Bandi and Russell's (2005c) results have been derived under the assumption that the microstructure noise is a covariance-stationary zero mean vector stochastic process that is independent of the vector of efficient (and unobservable) prices.

However, the estimation of integrated covariances using high-frequency data brings new important issues. As pointed out by Epps (1979), information arrives at different frequencies for different assets, therefore introducing additional microstructure effects that are related to the nonsynchronicity in the process of price formation. Even when there is no microstructure frictions as previously discussed, nonsynchronous trading introduces a downward bias in the realized covariance estimates when 
sampling returns in calendar time at high frequencies. This is the socalled Epps effect. To accommodate this effect, Bandi and Russell (2005b) incorporated leads and lags in their estimator. This is an old solution in the literature to overcome the nonsynchronicity of observations (see Cohen et al., 1983; Dimson, 1979; Scholes and Williams, 1977). For two given assets, Bandi and Russell's (2005c) lead-lag estimator with $U$ lags and $L$ leads is given by

$$
\operatorname{RCov}_{t,(1)(2)}^{(\mathrm{BR})}=\sum_{i=1}^{n_{t}^{*}} \sum_{s=-L}^{U} r_{(1) i, t} r_{(2) i-s, t}
$$

where $r_{(1) i, t}$ and $r_{(2) i, t}$ are the $i$ th intraday returns for asset (1) and (2) at day $t$. The optimal sampling frequency is given by (25).

As observed by Bandi and Russell (2006a), an interesting topic for future research is the use of direct MSE-based optimization of the leadlag estimator to determine the optimal sampling frequency as well as the choice of the number of leads and lags under the presence of microstructure noise. In a related work, Martens (2005) evaluated the MSE properties of a number of covariance estimators through simulations based on Lo and MacKinlay's (1990) nonsynchronous trade model.

\subsection{Recent Extensions}

Recently, Hayashi and Yoshida (2005, 2006), Sheppard (2006), and Zhang (2006b), among others, introduced alternative approaches to the high-frequency covariance estimator. For example, instead of using calendar time returns, the Hayashi and Yoshida (HY) estimator is based on overlapping tick-by-tick returns. In the absence of classical microstructure frictions, but in the presence of nonsynchronous trading, the HY estimator is consistent and asymptotically normally distributed. Sheppard (2006) analyzed the conditions under which the realized covariance is an unbiased and consistent estimator of the integrated variance. The concept of "scrambling" was defined by Sheppard (2006) to motivate a general family of alternative specifications based on random censoring of returns, which nests the previously suggested corrections for multivariate estimators. Zhang (2006b) also studied the effects of microstructure noise and nonsynchronous trading in the estimation of the integrated covariance between two assets. Zhang (2006b) showed that the bias is more pronounced in less liquid assets and provided a way, as in Bandi and Russell (2005b), to compute the optimal sampling frequency in order to reduce the bias.

Voev and Lunde (2006) and Griffin and Oomen (2006) provide detailed finite sample studies of the MSE properties of several covariance 
estimators, including the realized covariance, optimally-sampled realized covariance, the HY estimator, and the lead-lag estimator (in Equation (26)). The authors also provided recommendations for practical implementations of such estimators. Hoshikawa et al. (2008) compared the multivariate version of the Fourier estimator of Malliavin and Mancino (2002), the HY estimator, and the classical realized covariance estimator. The authors found that the HY estimator performs the best among the alternatives in view of the bias and the MSE, while the other estimators were shown to have possibly heavy bias, mostly toward the origin.

\section{MODELLING AND FORECASTING RV}

\subsection{Some Stylized Facts in Financial Time Series and Univariate Applications}

A well established result in the financial econometrics time series literature is that, when GARCH and SV latent volatility models are used, the standardized returns do not have a Gaussian distribution. In practice, there is still excess kurtosis, a fact that motivates the use of heavy-tailed distributions. However, Andersen et al. (2000a,b, 2001a, 2003) showed that, when the realized variance was used, the distribution of the standardized exchange rate series was almost Gaussian. This was also corroborated for stock returns in Andersen et al. (2001a). Furthermore, the logarithm of the realized volatilities was also nearly Gaussian.

Concerning the dynamics of the log-realized variance, it is well established that this is a highly persistent, but stationary, time series process. In addition, there is significant evidence of long memory in the time series, which has been conventionally modeled as an $\operatorname{ARFIMA}(p, d, q)$ process (see Andersen et al., 2000a,b, 2001a, 2003) for some examples). ${ }^{6}$ Recently, Corsi et al. (2001) and Corsi (2003) proposed the Heterogeneous AutoRegressive Realized Volatility (HAR-RV) model, based on the Heterogeneous ARCH (HARCH) model of Müller et al. (1997). The HAR-RV model is specified as a multicomponent volatility model with an additive hierarchical structure such that the volatility is specified as a sum of components over different horizons (see also Andersen et al., 2006a). McAleer and Medeiros (2006) extended the HAR-RV model by proposing a flexible multiple regime smooth transition model to capture nonlinearities and long-range dependence in the time series dynamics.

These results notwithstanding, identifying the possible sources of long memory is also of particular interest, such as in case of spurious long

\footnotetext{
${ }^{6}$ As one of the few exceptions, Carvalho et al. (2006) did not found evidence of long memory in the dynamics of realized volatilities for several assets traded in the Brazilian stock exchange.
} 
memory, where a short memory model may produce better and more precise forecasts. Recently, Hyung et al. (2005) discussed the possible sources of long memory in financial volatility. As outlined in Hyung et al. (2005), a myriad of nonlinear short memory models, especially models with infrequent breaks, can generate data with long memory behavior. Examples of such nonlinear models include the break model of Granger and Hyung (2004), the volatility component model of Engle and Lee (1999), the regime switching model proposed by Hamilton and Susmel (1994), and further discussed in Diebold and Inoue (2001), and the multiple-regime model of Medeiros and Veiga (2004). Hillebrand (2005) also discussed the effects of breaks on the estimation of volatility models (see also Hillebrand and Medeiros, 2006). Scharth and Medeiros (2006) proposed a multiple-regime model based on regression trees to describe the dynamics of realized volatilities of several DJIA stocks. The authors incorporated past cumulated daily returns as a source of regime switches. Their main finding is that this effect is highly significant and accounts for high empirical values of long memory parameter estimates. They also showed that the nonlinear model significantly outperformed the concurrent long memory models (ARFIMA and HAR-RV) in an out-ofsample experiment for all 16 stocks analyzed, especially in periods of high volatility.

In each of the specifications discussed above, volatility refers to short memory between breaks, for each volatility component, and within each regime. More recently, Martens et al. (2004) proposed a model that combines the long memory property with nonlinearity, which is especially important in modeling asymmetries and the leverage effect. They showed strong empirical evidence in favor of their proposal. Deo et al. (2006) considered a long-memory stochastic volatility model and Koopman et al. (2005) proposed a model combining unobserved components and longmemory. In a recent work, Hillebrand and Medeiros (2008) suggested a model that combines long memory with different types of nonlinearity. Their approach is based on a simultaneous equation framework, where volatility also direct affects the returns (as in the GARCH-in-Mean model). However, it is still an open question as to the source of the apparent long memory in the RV, and whether the benefits of combining long memory and nonlinear models will dramatically improve the accuracy in forecasting volatility (Ohanissian et al., 2004a,b).

More recently, Lieberman and Phillips (2008) have provided some analytical explanations for the long range dependence behavior that has been observed in RVs. The authors show that long memory may arise from the accumulation of RV, and discussed how to refine the statistical inference regarding the parameter $d$ in $\operatorname{ARFIMA}(p, d, q)$ models.

Ait-Sahalia and Mancini (2006) compare the out-of-sample relative forecasting ability of RV in a variety of contexts. Ghysels and Sinko (2006) 
analyze the relative predictive ability of realized volatility within the mixed data sampling (MIDAS) framework of Ghysels et al. (2006). Corradi et al. (2006) focused on estimating and forecasting the conditional density of integrated volatility and Corsi et al. (2008) focused on the volatility of the realized volatility.

Another issue that should be mentioned is the fact that, even without the presence of microstructure noise, $\mathrm{RV}$ is an estimated quantity rather than the true daily volatility (or integrated variance), and integrated quarticity is replaced by realized quarticity. This leads to the use of generated regressors and generated variables for purposes of forecasting, with the associated critical issues of efficient estimation and invalid inferences that arise through the use of biased (asymptotic) standard errors (see McKenzie and McAleer, 1997; Pagan, 1984, 1986 for comprehensive discussions).

Recently, Andersen et al. (2004, 2005) have developed a general model-free adjustment procedure for the calculation of unbiased volatility loss functions based on realized volatility benchmarks. The authors have also shown that properly accounting for the measurement errors in the volatility forecast evaluations reported in the existing literature can lead to markedly higher estimates for the true degree of returns volatility predictability. In a recent article, Corradi and Distaso (2006) proposed a procedure to test for the correct specification of the functional form of the volatility process based on the class of eigenfunction stochastic volatility models of Meddahi (2001). Their idea is to compare the moments of the RV measures with the corresponding ones of the integrated volatility implied by the theoretical model under the null hypothesis. The authors carefully took account of the fact that RV is an estimated measure, and is thereby contaminated with measurement errors.

\subsection{Multivariate Applications}

In an interesting article, de Pooter et al. (2008) investigate the benefits of high frequency intraday data when constructing mean-variance efficient stock portfolios with daily rebalancing from the individual constituents of the S\&P 100 index. The authors analyzed the issue of determining the optimal sampling frequency, as judged by the performance of the estimated portfolios. The optimal sampling frequency ranges between 30 and 65 minutes, that is, much lower than the five-minute frequency, which is commonly used in the literature. The authors also showed that several bias-correction procedures, based on combining low and high-frequency covariance matrix estimates, and with the addition of leads and lags, do not substantially affect the optimal sampling frequency or the portfolio performance. The findings are also robust to the presence of transaction costs and to the portfolio rebalancing frequency. 
In a related article, Bandi et al. (2008) evaluate the economic benefits of methods that have been suggested to optimally-sample (in an MSE sense) high-frequency return data for the purpose of realized variance and covariance estimation in the presence of market microstructure noise. The authors compared certainty equivalents derived from volatility-timing trading strategies, relying on optimally-sampled realized variances and covariances, on realized variances and covariances obtained by sampling every 5 minutes, and on realized variances and covariances obtained by sampling every 15 minutes. They showed that a risk-averse investor, who is given the option of choosing variance and covariance forecasts derived from MSE-based optimal sampling methods versus forecasts obtained from 5- and 15-minute intervals (as is generally proposed in the literature), would be willing to pay up to about 80 basis points per year to achieve the level of utility that is guaranteed by optimal sampling. They also found that the gains yielded by optimal sampling are economically large and statistically significant.

Bauer and Vorkink (2006) present a new matrix logarithm model of the realized covariance of stock returns, which uses latent factors as functions of both lagged volatility and returns. The model has several advantages in that it is parsimonious, does not require imposing parametric restrictions, and yields a positive definite covariance matrix. The model is applied to the covariance matrix of size sorted stock returns, and two factors are found to be sufficient to capture most of the dynamics.

\section{CONCLUDING REMARKS}

This article provided a critical view of the main developments in the exciting and rapidly expanding literature on RV. A simple discrete time model was presented in order to motivate the main results, with a continuous time specification providing the theoretical foundation for the main results in this literature. Cases with and without microstructure noise were considered, and it was shown how microstructure noise could cause severe problems in terms of consistent estimation of the daily RV estimator. Independent and dependent noise processes were carefully examined. For purposes of informing the practitioner, the review article sought to fill the gaps in the literature, especially regarding the issues of modeling and forecasting daily RVs. The most important solutions currently available for the consistency problem were presented, a critical exposition of different techniques was given, the finite sample properties were discussed in comparison with their asymptotic properties, a multivariate model was presented to discuss estimation of the realized covariances, various issues relating to modeling and forecasting realized volatilities were considered, different modelling strategies were suggested, 
model evaluation was discussed, and the most important empirical findings and practical applications for univariate and multivariate models were summarized.

There are many problems that remain unresolved and unsolved in the RV literature, especially for multivariate processes with a very large number of assets. In the near future, multivariate RV processes alone will require an extensive review as the challenge for new models and estimators is met and solutions are realized.

\section{ACKNOWLEDGMENTS}

The authors wish to acknowledge the insightful comments and suggestions of two anonymous referees, seminar participants at Chiang Mai University, Thailand, and Keio University, Japan, and very helpful discussions with Yacine Aït-Sahalia, Manabu Asai, Federico Bandi, Felix Chan, Kim Christensen, Dick van Dijk, Marcelo Fernandes, Jiti Gao, Peter Hansen, Offer Lieberman, Asger Lunde, Essie Maasoumi, Colin McKenzie, Nour Meddahi, Kimio Morimune, Per Mykland, Roel Oomen, Neil Shephard, and Songsak Sriboonchitta. The first author wishes to acknowledge the financial support of an Australian Research Council Discovery Grant, and the second author wishes to thank the CNPq/Brazil for partial financial support.

\section{REFERENCES}

Ait-Sahalia, Y., Mancini, L. (2006). Out of Sample Forecasts of Quadratic Variation. Working Paper, Princeton University. To appear in Journal of Econometrics.

Ait-Sahalia, Y., Mykland, P. A., Zhang, L. (2005). How often to sample a continuous time process in the presence of market microstructure noise. Review of Financial Studies 18:351-416.

Ait-Sahalia, Y., Mykland, P. A., Zhang, L. (2006). Ultra High Frequency Volatility Estimation with Dependent Microstructure Noise. Working Paper, w11380, NBER.

Amihud, Y., Mendelson, H. (1987). Trading mechanisms and stock returns: an empirical investigation. Journal of Finance 42:533-553.

Andersen, T. G., Bollerslev, T. (1997). Intraday periodicity and volatility persistence in financial markets. Journal of Empirical Finance 4:115-158.

Andersen, T. G., Bollerslev, T. (1998). Answering the skeptics: Yes, standard volatility models do provide accurate forecasts. International Economic Review 39:885-905.

Andersen, T. G., Bollerslev, T., Lange, S. (1999). Forecasting financial market volatility: Sample frequency vis-a-vis forecast horizon. Journal of Empirical Finance 6:457-477.

Andersen, T. G., Bollerslev, T., Diebold, F. X., Labys, P. (2000a). Exchange rate returns standardized by realized volatility are (nearly) Gaussian. Multinational Finance Journal 4:159-179.

Andersen, T. G., Bollerslev, T., Diebold, F. X., Labys, P. (2000b). Great realizations. Risk 13:105-108.

Andersen, T. G., Bollerslev, T., Diebold, F. X., Ebens, H. (2001a). The distribution of realized stock return volatility. Journal of Financial Economics 61:43-76.

Andersen, T. G., Bollerslev, T., Diebold, F. X., Labys, P. (2001b). The distribution of exchange rate volatility. Journal of the American Statistical Association 96:42-55 (Correction, 2003, 98, 501).

Andersen, T. G., Bollerslev, T., Diebold, F. X., Labys, P. (2003). Modeling and forecasting realized volatility. Econometrica 71:529-626. 
Andersen, T. G., Bollerslev, T., Meddahi, N. (2004). Analytic evaluation of volatility forecasts. International Economic Review 45:1079-1110.

Andersen, T. G., Bollerslev, T., Meddahi, N. (2005). Correcting the errors: Volatility forecast evaluation using high-frequency data and realized volatilities. Econometrica 73:279-296.

Andersen, T. G., Bollerslev, T., Christoffersen, P., Diebold, F. X. (2006a). Volatility and correlation forecasting. In: Elliott, G., Granger, C. W. J., Timmermann, A., eds. Handbook of Economic Forecasting. Amsterdam: North-Holland, pp. 778-878.

Andersen, T. G., Bollerslev, T., Christoffersen, P., Diebold, F. X. (2006b). Practical volatility and correlation modeling for financial market risk management. In: Carey, M., Stulz, R., eds. Risks of Financial Institutions. Chicago: University of Chicago Press for NBER.

Andersen, T. G., Bollerslev, T., Diebold, F. X. (2006c). Parametric and nonparametric measurement of volatility. In: Aït-Sahalia, Y., Hansen, L. P., eds. Handbook of Financial Econometrics. Amsterdam: North-Holland.

Andersen, T. G., Bollerslev, T., Diebold, F. X. (2007). Roughing it up: Including jump components in the measurement, modeling and forecasting of return volatility. Review of Economics and Statistics 89:701-720.

Andrews, D. W. K. (1991). Heteroskedasticity and autocorrelation consistent covariance matrix estimation. Econometrica 59:817-858.

Asai, M., McAleer, M., Yu, J. (2006). Multivariate stochastic volatility: a review. Econometric Reviews 25:145-175.

Bandi, F. M., Russell, J. R. (2005a). Microstructure noise, realized volatility, and optimal sampling. Unpublished paper. Graduate School of Business, University of Chicago.

Bandi, F. M., Russell, J. R. (2005b). Realized covariation, realized beta and microstructure noise. Unpublished paper. Graduate School of Business, University of Chicago.

Bandi, F. M., Russell, J. R. (2006a). Volatility. In: Birge, J. R., Linetsky, V., eds. Handbook of Financial Engineering. Elsevier.

Bandi, F. M., Russell, J. R. (2006b). Separating market microstructure noise from volatility. Journal of Financial Economics 79:655-692.

Bandi, F. M., Russell, J. R. (2006c). Comment on Hansen and Lunde. Journal of Business and Economic Statistics 24:167-173.

Bandi, F. M., Russell, J. R. (2006d). Market microstructure noise, integrated variance estimators, and the accuracy of asymptotic approximations. Unpublished paper. Graduate School of Business, University of Chicago.

Bandi, F., Russell, J. R., Zhu, Y. (2008). Using high-frequency data in dynamic portfolio choice. Econometric Reviews 27:163-198.

Barndorff-Nielsen, O. E., Shephard, N. (2002). Econometric analysis of realised volatility and its use in estimating stochastic volatility models. Journal of the Royal Statistical Society B 64:253-280.

Barndorff-Nielsen, O. E., Shephard, N. (2004a). Power and bipower variation with stochastic volatility and jumps (with discussion). Journal of Financial Econometrics 2:1-48.

Barndorff-Nielsen, O. E., Shephard, N. (2004b). Econometric analysis of realised covariation: high frequency based covariance, regression and correlation in financial economics. Econometrica 72:885-925.

Barndorff-Nielsen, O. E., Shephard, N. (2005a). Power variation and time change. Theory of Probability and Its Applications 50:1-15.

Barndorff-Nielsen, O. E., Shephard, N. (2005b). How accurate is the asymptotic approximation to the distribution of realised volatility? In: Andrews, D. W. K., Stock, J. H., eds Identification and Inference for Econometric Models. A Festschrift for Tom Rothenberg. Cambridge: Cambridge University Press, pp. 306-331.

Barndorff-Nielsen, O. E., Shephard, N. (2007). Variation, jumps and high frequency data in financial econometrics. In: Blundell, R., Torsten, P. Newey, W. K., eds. Advances in Economics and Econometrics: Theory and Applications, Ninth World Congress. Econometric Society Monograph, Cambridge University Press.

Barndorff-Nielsen, O. E., Hansen, P. H., Lunde, A., Shephard, N. (2006a). Designing realised kernels to measure the ex-post variation of equity prices in the presence of noise. Unpublished manuscript. Stanford University.

Barndorff-Nielsen, O. E., Hansen, P. H., Lunde, A., Shephard, N. (2006b). Subsampling realised kernels. Unpublished manuscript. Stanford University. 
Barndorff-Nielsen, O. E., Graversen, S. E., Jacod, J., Shephard, N. (2006c). Limit theorems for realized bipower variation in econometrics. Econometric Theory 22:677-719.

Barucci, E., Reno, R. (2002a). On measuring volatility and the GARCH forecasting performance. Journal of International Financial Markets, Institutions and Money 12:183-200.

Barucci, E., Reno, R. (2002b). On measuring volatility of diffusion processes with high frequency data. Economics Letters 74:371-378.

Bauer, G. H., Vorkink, K. (2006). Multivariate realized stock market volatility. Paper presented to CIREQ Conference on Realized Volatility, Montreal, Canada.

Biais, B., Glosten, L., Spatt, C. (2005). Market microstructure: A survey of microfoundations, empirical results, and policy implications. Journal of Financial Markets 8:217-264.

Black, F. (1976). Noise. Journal of Finance 41:529-543.

Bollen, B., Inder, B. (2002). Estimating daily volatility in financial markets utilizing intraday data. Journal of Empirical Finance 9:551-562.

Bollerslev, T. (1986). Generalized autoregressive conditional heteroskedasticity. Journal of Econometrics 21:307-328.

Bollerslev, T. (1987). A conditionally heteroskedastic time series model for speculative prices and rates of return. Review of Economics and Statistics 69:542-547.

Bollerslev, T., Kretschmer, U., Pigorsch, C., Tauchen, G. (2005). The dynamics of bipower variation, realized volatility and returns. Unpublished manuscript. Department of Economics, Duke University.

Carnero, M. A., Peña, D., Ruiz, E. (2004). Persistence and kurtosis in GARCH and stochastic volatility models. Journal of Financial Econometrics 2:319-342.

Carvalho, M. R. C., Freire, M. A. S., Medeiros, M. C., Souza, L. R. (2006). Modeling and forecasting the volatility of Brazilian asset returns: a realized variance approach. Revista Brasileira de Finanças 4:321-343.

Cohen, K. J., Hawanini, G. A., Maier, S. F., Schwartz, R. A., Whitcomb, D. K. (1983). Friction in the trading process and the estimation of systematic risk. Journal of Financial Economics 12:263-278.

Christensen, K., Podolskij, M. (2006a). Realized range-based estimation of integrated variance. To appear in Journal of Econometrics.

Christensen, K., Podolskij, M. (2006b). Range-Based Estimation of Quadratic Variation. Working Paper, Aarhus School of Business.

Corradi, V., Distaso, W. (2006). Semiparametric comparison of stochastic volatility models via realized measures. Review of Economic Studies 73:635-677.

Corradi, V., Distaso, W., Swanson, N. R. (2006). Predictive Inference for Integrated Volatility. Working Paper, Rutgers University.

Corsi, F. (2003). A Simple Long Memory Model of Realized Volatility. Working Paper, University of Southern Switzerland.

Corsi, F., Zumbach, G., Müller, U., Dacorogna, M. (2001). Consistent high-precision volatility from high frequency data. Economic Notes 30:183-204.

Corsi, F., Mittnik, S., Pigorsch, C., Pigorsch, U. (2008). The volatility of realized volatility. Econometric Reviews 27:46-78.

Curci, G., Corsi, F. (2004). Discrete Sine Transform Approach for Realized Volatility Measurement. Working Paper, University of Southern Switzerland.

Dacorogna, M., Gencay, R., Müller, U., Olsen, R. B., Pictet, O. V. (2001). An Introduction to HighFrequency Finance. London: Academic Press.

Deo, R., Hurvich, C., Lu, Y. (2006). Forecasting realized volatility using a long-memory stochastic volatility model: estimation, prediction and seasonal adjustment. Journal of Econometrics 131:29_ 58.

Diebold, F. X., Inoue, A. (2001). Long memory and regime switching. Journal of Econometrics 105:131-159.

Dimson, E. (1979). Risk management when shares are subject to infrequent trading. Journal of Financial Economics 7:197-226.

Ebens, H. (1999). Realized Stock Index Volatility. Working Paper No. 420, Department of Economics. Johns Hopkins University, Baltimore.

Engle, R. F. (1982). Autoregressive conditional heteroskedasticity with estimates of the variance of United Kingdom inflation. Econometrica 50:987-1007. 
Engle, R. F., Lee, G. J. (1999). A long-run and short-run component model of stock return volatility. In: Engle, R., White, H., eds. Cointegration, Causality, and Forecasting: A Festschrift in Honour of Clive W.J. Granger, Chapter 10. Oxford: University Press, pp. 475-497.

Epps, T. W. (1979). Comovements in stock prices in the very short run. Journal of the American Statistical Association 74:291-298.

Fleming, J., Kirby, C., Ostdiek, B. (2001). The economic value of volatility timing. Journal of Finance 56:329-352.

Fleming, J., Kirby, C., Ostdiek, B. (2003). The economic value of volatility timing using "realized volatility". Journal of Financial Economics 67:473-509.

Ghysels, E., Sinko, A. (2006). Volatility Forecasting and Microstructure Noise. Working Paper, University of North Carolina.

Ghysels, E., Santa-Clara, P., Valkanov, R. (2006). Predicting volatility: Getting the most out of return data sampled at different frequencies. To appear in Journal of Econometrics.

Gonçalves, S., Meddahi, N. (2005). Boostraping Realized Volatility. Working Paper, Université de Montréal.

Gonçalves, S., Meddahi, N. (2008). Edgeworth corrections for realized volatility. Econometric Reviews 27:139-162.

Granger, C. W. J., Hyung, N. (2004). Occasional Structural Breaks and Long Memory. Working Paper 99-14, San Diego: University of California.

Griffin, J. E., Oomen, R. C. A. (2006). Covariance Measurement in the Presence of Nonsynchronous Trading and Market Microstructure Noise. Working Paper, Warwick Business School.

Griffin, J. E., Oomen, R. C. A. (2008). Sampling Returns for Realized Variance Calculations: Tick Time or Transaction Time? Econometric Reviews 27:230-253.

Hamilton, J. D., Susmel, R. (1994). Autoregressive conditional heteroskedasticity and changes in regime. Journal of Econometrics 64:307-333.

Hansen, P. R., Large, J., Lunde, A. (2008). Moving average-based estimators of integrated variance. Econometric Reviews 27:79-111.

Hansen, P. R., Lunde, A. (2004). An unbiased measure of realized variance. Unpublished manuscript. Stanford University.

Hansen, P. R., Lunde, A. (2005a). A forecast comparison of volatility models: Does anything beat a $\operatorname{GARCH}(1,1)$ ? Journal of Applied Econometrics 20:873-889.

Hansen, P. R., Lunde, A. (2005b). A realized variance for the whole day based on intermittent high-frequency data. Journal of Financial Econometrics 3:525-554.

Hansen, P. R., Lunde, A. (2006a). Consistent ranking of volatility models. Journal of Econometrics 131:97-121.

Hansen, P. R., Lunde, A. (2006b). Realized variance and market microstructure noise (with discussion), Journal of Business and Economic Statistics 24:127-218.

Harris, L. (1990). Estimation of stock variance and serial covariance from discrete observations. Journal of Financial and Quantitative Analysis 25:291-306.

Harris, L. (1991). Stock price clustering and discreteness. Review of Financial Studies 4:389-415.

Hasbrouck, J. (2004). Empirical market microstructure: Economic and statistical perspectives on the dynamics of trade in securities markets. Lecture Notes. Stern School of Business, New York University.

Hayashi, T., Yoshida, N. (2005). On covariance estimation of non-synchronously observed diffusion processes. Bernoulli 11:359-379.

Hayashi, T., Yoshida, N. (2006). Estimating Correlations with Nonsynchronous Observations in Continuous Diffusion Models. Working Paper, Columbia University.

Hillebrand, E. (2005). Neglecting parameter changes in GARCH models. Journal of Econometrics 129:121-138.

Hillebrand, E., Medeiros, M. C. (2006). Estimating and forecasting GARCH models in the presence of structural breaks and regime switches. In: Rapach, D., Wohar, M., eds. Forecasting in the Presence of Structural Breaks and Uncertainty. Frontiers of Economics and Globalization. Elsevier.

Hillebrand, E., Medeiros, M. C. (2008). Asymmetries, Breaks, and Long-Range Dependence: An Estimation Framework for Times Series of Daily Realized Volatility. Working Paper, Louisiana State University.

$\mathrm{Høg}$, E., Lunde, A. (2003), Wavelet Estimation of Integrated Volatility. Working Paper, Aarhus School of Business. 
Hoshikawa, T., Kanatani, T., Nagai, K., Nishiyama, Y. (2008). Nonparametric methods of integrated multivariate volatilities. Econometric Reviews 27:112-138.

Huang, X., Tauchen, G. (2005), The relative contribution of jumps to total price variance, unpublished manuscript. Journal of Financial Econometrics 3:456-499.

Hyung, N., Poon, S.-H., Granger, C. W. J. (2005). The Source of Long Memory in Financial Market Volatility. Working Paper, University of California at San Diego.

Jacod, J., Protter, P. (1998), Asymptotic error distributions for the Euler method for stochastic differential equations. Annals of Probability 26:267-307.

Koopman, S. J., Jungbacker, B., Hol, E. (2005). Forecasting daily variability of the S\&P 100 stock index using historical, realised and implied volatility measurements. Journal of Empirical Finance 12:445-475.

Large, J. (2006). Estimating Quadratic Variation When Quoted Prices Jump by a Constant Increment. Unpublished paper. Nuffield College, Oxford.

Lieberman, O., Phillips, P. C. B. (2008). Refined inference on long memory in realized volatility. Econometric Reviews 27:254-267.

Lo, A. W., MacKinlay, C. (1990). An econometric analysis of nonsynchronous trading. Journal of Econometrics 45:181-212.

Madhavan, A. (2000). Market microstructure: a survey. Journal of Financial Markets 3:205-258.

Maheu, J. M., McCurdy, T. H. (2002). Nonlinear features of realized FX volatility. Review of Economics and Statistics 84:668-681.

Malliavin, P., Mancino, M. E. (2002). Fourier series method for measurement of multivariate volatilities. Finance and Stochastics 6:49-61.

Malmsten, H., Teräsvirta, T. (2004). Stylized Facts of Financial Time Series and Three Popular Models of Volatility. Working Paper, Series in Economics and Finance 563, Stockholm School of Economics.

Martens, M. (2001). Forecasting daily exchange rate volatility using intraday returns. Journal of International Money and Finance 20:1-23.

Martens, M. (2002). Measuring and forecasting S\&P 500 index-futures volatility using high-frequency data. Journal of Futures Markets 22:497-518.

Martens, M. (2005). Estimating Unbiased and Precise Realized Covariances. Unpublished paper. Erasmus University Rotterdam.

Martens, M., van Dijk, D., de Pooter, M. (2004). Modeling and forecasting S\&P 500 volatility: Long memory, structural breaks and nonlinearity, Tinbergen Institute Discussion Paper 04-067/4.

McAleer, M. (2005). Automated inference and learning in modeling financial volatility. Econometric Theory 21:232-261.

McAleer, M., Medeiros, M. C. (2006). A Multiple Regime Smooth Transition Heterogeneous Autoregressive Model for Long Memory and Asymmetries. Working Paper, Pontifical Catholic University of Rio de Janeiro. To appear in Journal of Econometrics.

McKenzie, C. R., McAleer, M. (1997). On efficient estimation and correct inference in models with generated regressors: A general approach. Japanese Economic Review 48:368-389.

Meddahi, N. (2001). An Eigenfunction Approach for Volatility Modeling. Working Paper, Université de Montréal.

Meddahi, N. (2002). A theoretical comparison between integrated and realized volatility. Journal of Applied Econometrics 17:479-508.

Medeiros, M. C., Veiga, A. (2004). Modeling Multiple Regimes in Financial Volatility with a Flexible Coefficient GARCH(1,1) Model. Discussion paper 486, Pontifical Catholic University of Rio de Janeiro.

Merton, R. C. (1980). On estimating the expected return on the market: An exploratory investigation. Journal of Financial Economics 8:323-361.

Morgan, J. P. (1996). J.P. Morgan/Reuters Riskmetrics - Technical Document. New York: J.P. Morgan.

Müller, U. A., Dacorogna, M. M., Davé, R. D., Olsen, R. B., Puctet, O. V., von Weizsäcker, J. (1997). Volatilities of different time resolutions - Analyzing the dynamics of market components. Journal of Empirical Finance 4:213-239.

Mykland, P. A., Zhang, L. (2006). ANOVA for diffusions and Ito processes. Annals of Statistics 33.

Newey, W. K., West, K. D. (1987). A simple positive semi-definite, heteroskedasticity and autocorrelation consistent covariance matrix. Econometrica 55:703-708. 
Nielsen, M.Ø., Frederiksen, P. H. (2006). Finite Sample Accuracy and Choice of Sampling Frequency in Integrated Volatility Estimation. Working Paper, Cornell University.

O’Hara, M. (1995). Market Microstructure Theory. Oxford: Blackwell.

Ohanissian, A., Russell, J. R., Tsay, R. (2004a). True or Spurious Long Memory: Does it Matter for Pricing Options?. Unpublished manuscript. Graduate School of Business, University of Chicago.

Ohanissian, A., Russell, J. R., Tsay, R. (2004b). True or Spurious Long Memory? A New Test. Unpublished manuscript. Graduate School of Business, University of Chicago.

Oomen, R. C. A (2002). Modelling Realized Variance when Returns are Serially Correlated. Unpublished manuscript. Warwick Business School, University of Warwick.

Oomen, R. C. A (2005). Properties of bias-corrected realized variance under alternative sampling schemes. Journal of Financial Econometrics 3:555-577.

Oomen, R. C. A (2006). Properties of realized variance under alternative sampling schemes. Journal of Business and Economic Statistics 24:219-237.

Pagan, A. R. (1984). Econometric issues in the analysis of regressions with generated regressors. International Economic Review 25:221-247.

Pagan, A. R. (1986). Two stage and related estimators and their applications. Review of Economic Studies 53:517-538.

Patton, A. (2005). Volatility Forecast Evaluation and Comparison Using Imperfect Volatility Proxies. Unpublished manuscript. London School of Economics.

Poon, S., Granger, C. W. J. (2003). Forecasting volatility in financial markets: A review. Journal of Economic Literature 41:478-539.

de Pooter, M., Martens, M., van Dijk, D. (2008). Predicting the daily covariance matrix for S\&P 100 stocks using intraday data - but which frequency to use?. Econometric Reviews 27:199-229.

Rootzen, H. (1980). Limit distributions for the error in approximations of stochastic integrals. Annals of Probability 8:241-251.

Scharth, M., Medeiros, M. C. (2006). Asymmetric Effects and Long Memory in the Volatility of DJIA Stocks. Working Paper, Pontifical Catholic University of Rio de Janeiro.

Scholes, M., Williams, J. (1977). Estimating betas from nonsynchronous data. Journal of Financial Economics 5:309-327.

Sheppard, K. (2006). Realized Covariance and Scrambling. Working Paper, University of Oxford.

Sun, Y. (2006). Best Quadratic Unbiased Estimators of Integrated Variance. Working Paper, University of California at San Diego.

Taylor, S. J. (1986). Modelling Financial Time Series. Chichester: Wiley.

Tauchen, G., Zhou, H. (2004). Identifying Realized Jumps on Financial Markets. Unpublished manuscript. Department of Economics, Duke University.

van Dijk, D., Martens, M. (2007). Measuring volatility with the realized range. Journal of Econometrics 138:181-207.

Voev, V., Lunde, A. (2006). Integrated Covariance Estimation Using High-Frequency Data in the Presence of Noise. Working Paper, Aarhus School of Business.

Wasserfallen, W., Zimmermann, H. (1985). The behavior of intraday exchange rates. Journal of Banking and Finance 9:55-72.

Zhang, L. (2006a). Efficient estimation of stochastic volatility using noisy observations: A multi-scale approach. Bernoulli 12:1019-1043.

Zhang, L. (2006b). Estimating Covariation: Epps Effect, Microstructure Noise. Working Paper, University of Illinois at Chicago.

Zhang, L., Mykland, P. A., Aït-Sahalia, Y. (2005). A tale of two time scales: determining integrated volatility with noisy high frequency data. Journal of the American Statistical Association 100:1394-1411.

Zhou, B. (1996). High frequency data and volatility in foreign-exchange rates. Journal of Business and Economic Statistics 14:45-52. 